\title{
Ammonium persulfate can initiate an asthmatic response in mice
}

\author{
Vanessa De Vooght, ${ }^{1}$ María-Jesús Cruz, ${ }^{2}$ Steven Haenen, ${ }^{1}$ Katlijn Wijnhoven, ${ }^{1}$ \\ Xavier Muñoz, ${ }^{2}$ Peter HM Hoet, ${ }^{1}$ Ferran Morell, ${ }^{2}$ Benoit Nemery, ${ }^{1}$ \\ Jeroen AJ Vanoirbeek ${ }^{1}$
}

\begin{abstract}
${ }^{1}$ Research Unit of Lung Toxicology (Laboratory of Pneumology). KU Leuven, Leuven, Belgium

${ }^{2}$ Servei de Pneumologia, Hospital Vall d'Hebron, Barcelona, Spain
\end{abstract}

\section{Correspondence to} Dr María-Jesús Cruz, Servei de Pneumologia, Pg. Vall d'Hebron 119, 08035 Barcelona, Spain; mjcruz@ir.vhebron.net

VDV and M-JC contributed equally to this work. $\mathrm{M}-\mathrm{JC}, \mathrm{XM}$ and FM are members of the CIBER de Enfermedades Respiratorias (CIBERES), Spain.

Received 10 June 2009 Accepted 2 December 2009

\begin{abstract}
Background Persulfate salts are the main cause of occupational asthma (OA) in hairdressers. The aim of this study was to verify whether ammonium persulfate $\left(\left(\mathrm{NH}_{4}\right)_{2} \mathrm{~S}_{2} \mathrm{O}_{8}, \mathrm{AP}\right)$ is capable of triggering an asthma-like response in mice.
\end{abstract}

Methods BALB/c mice were dermally treated on days 1 and 8 , with dimethylsulfoxide (DMSO), $1 \%$ AP or $5 \%$ AP (20 $\mu \mathrm{l} / \mathrm{ear})$. On day 15 , the auricular lymph nodes were removed and an in vitro lymphocyte proliferation test (LPT) was performed. AP was tested for its ability to elicit an asthmatic response using a locally developed mouse model of chemical-induced asthma. On days 1 and 8 , BALB/C mice received $20 \mu \mathrm{AP}(5 \%)$ or DMSO on each ear. On day 15, they received an intranasal instillation of AP $(1 \%)$ or saline. Afterwards, ventilatory, inflammatory and immunological parameters were assessed.

Results The LPT showed that in vitro stimulation of lymphocytes with AP leads to specific proliferation of lymphocytes from AP-sensitised mice. In vivo, AP induced, in AP-sensitised mice only, an 'early' ventilatory response (increased Penh (enhanced pause))

immediately after challenge, and airway hyper-reactivity to methacholine $22 \mathrm{~h}$ later. Pulmonary inflammation was mainly characterised by neutrophils (10-15\%). AP-

sensitised mice showed an increase in total number of $T$ helper (Th) and B lymphocytes together with an increased in vitro secretion of interleukin-4 (IL-4), IL-10 and IL-13 and an increase in total serum immunoglobulin $E$.

Conclusions In a mouse model, it was confirmed that dermal sensitisation to AP can lead to asthma-like responses after a single administration via the airway.

\section{INTRODUCTION}

Occupational exposures are estimated to be responsible for $10-25 \%$ of all asthma cases in adults. ${ }^{1}$ Occupational asthma $(\mathrm{OA})$ is one of the most frequent forms of lung-related occupational diseases in the industrialised world. ${ }^{2}$ The prevalence of occupational asthma is mostly dependent on the nature of the agents and the exposure concentrations, and less on host-dependent factors such as atopy and smoking status. ${ }^{3} 4$ Persulfate salts are a well-known cause of $O A$ and, according to French and Catalonian registries of $\mathrm{OA}$, persulfates are the second most frequent cause of OA in women. ${ }^{5-7}$

Persulfate salts are highly reactive low molecular weight chemical compounds that are widely used for various manufacturing processes in the chemical, pharmaceutical, metallurgic, textile, photographic, food and, especially, cosmetic industries. ${ }^{8}$ These salts are capable of causing immunological sensitisation and subsequent allergic disease, such as contact dermatitis and bronchial asthma, and they are reputed to be the main cause of $\mathrm{OA}$ in hairdressers. $^{9-14}$

The mechanisms by which persulfate salts induce sensitisation and $\mathrm{OA}$ in hairdressers remain unknown. Some authors suggested that mast cells and T cells may play a role in the pathogenesis of the asthmatic reactions following inhalation of persulfate salts. $^{8} 13$ Muñoz et al suggested that this immunological mechanism might be mediated by immunoglobulin $\mathrm{E}(\operatorname{IgE})$, since a positive skin prick test to persulfate salts and elevated total serum IgE levels was found in some patients, which was also observed in $\sim 50 \%$ of cases published to date. $.^{12} 13 \quad 15-17$ However, not all subjects with demonstrated persulfate asthma have a positive skin prick test to persulfates.

Previously, we demonstrated, using the murine local lymph node assay, that ammonium persulfate $\left(\left(\mathrm{NH}_{4}\right)_{2} \mathrm{~S}_{2} \mathrm{O}_{8} ; \mathrm{AP}\right)$ is a moderate dermal sensitiser. ${ }^{18}$ In this study, we further investigated the lymphocyte-specific response to AP in an in vitro lymphocyte proliferation test (LPT) and the potential of AP to induce an asthma-like response using a validated mouse model of chemical-induced asthma based on dermal sensitisation and an intranasal challenge. ${ }^{19-21}$

\section{MATERIALS AND METHODS Animals}

Male BALB/c mice ( $20 \mathrm{~g}, 6$ weeks old) were obtained from Harlan (Horst, The Netherlands). The mice were housed in filter top cages in a conventional animal house with $12 \mathrm{~h}$ dark/light cycles and received lightly acidified water and pelleted food (Trouw Nutrition, Gent, Belgium) ad libitum. All experimental procedures were approved by the local Ethical Committee for Animal Experiments.

\section{Lymphocyte proliferation test}

On days 1 and 8 , the mice received dermal applications of AP $\left(\left(\mathrm{NH}_{4}\right)_{2} \mathrm{~S}_{2} \mathrm{O}_{8}\right.$, CAS 7727-54-0) $(1 \%$ or $5 \%$ ), vehicle (dimethylsulfoxide (DMSO)) $(20 \mu \mathrm{l})$ or nothing (naïve) on both ears. On day 15, the auricular draining lymph nodes were excised, pooled (five mice) and kept on ice in RPMI-1640 (Invitrogen, Merelbeke, Belgium). Cell suspensions were obtained by pressing the lymph nodes through a cell strainer $(100 \mu \mathrm{m})$ and rinsing with $5 \mathrm{ml}$ of RPMI1640 tissue culture medium. Cells were counted using a Bürker haemocytometer. Lymphocytes were washed twice with $5 \mathrm{ml}$ of tissue culture medium and centrifuged $\left(1000 \mathrm{~g}, 10 \mathrm{~min}, 4^{\circ} \mathrm{C}\right)$. The pellets 
were resuspended in complete tissue culture medium (RPMI1640 supplemented with $10 \%$ heat-inactivated fetal bovine serum, $10 \mathrm{mg} / \mathrm{ml}$ streptomycin, $100 \mathrm{IU} / \mathrm{ml}$ penicillin) at concentrations of $10^{7}$ cells $/ \mathrm{ml}$. One hundred thousand cells were incubated with or without AP $(0.0001 \%, 0.001 \%$ or $0.01 \%$, dissolved in complete medium) in $200 \mu \mathrm{l}$ of complete medium with $20 \mu \mathrm{Ci}$ of $\left[\right.$ methyl- $\left.{ }^{3} \mathrm{H}\right]$ thymidine $\left({ }^{3} \mathrm{H}\right] \mathrm{TdR}$, ICN Pharmaceuticals, Asse, Belgium) per well, in 96-well culture plates. After $18 \mathrm{hs}$, cells were centrifuged at $1000 \mathrm{~g}$ for $10 \mathrm{~min}$ at $4^{\circ} \mathrm{C}$. Supernatants were discarded and the cells were washed twice with phosphate-buffered saline $\left(\mathrm{PBS}^{+}\right)$and once with $1 \mathrm{ml}$ of $5 \%$ trichloroacetic acid (TCA; Sigma-Aldrich, Bornem, Belgium). The cells were then resuspended in $5 \%$ TCA $(5 \mathrm{ml})$ and stored overnight at $4^{\circ} \mathrm{C}$. After centrifugation $\left(1000 \mathrm{~g}, 10 \mathrm{~min}, 4^{\circ} \mathrm{C}\right)$ the pellets were resuspended in $500 \mu \mathrm{l}$ of $5 \%$ TCA and transferred to $5 \mathrm{ml}$ of scintillation fluid (ultima gold, PerkinElmer, Groningen, The Netherlands). The incorporation of $\left[{ }^{3} \mathrm{H}\right] \mathrm{TdR}$ was measured by $\beta$-scintillation (Beckman LS 5000CE, Irvine, California, USA) and expressed as counts per minute (cpm). Each time, the lymph nodes of five control or AP-treated mice were pooled and each in vitro AP proliferation assay was performed in five replicates. In total an average $( \pm \mathrm{SD}) \mathrm{cpm}$ is calculated.

\section{Mouse model of chemical-induced asthma}

On days 1 and 8 , the animals received dermal applications of 5\% AP or vehicle (DMSO) on the dorsum of both ears $(20 \mu \mathrm{l})$. On day 15, they received, under light anaesthesia with isoflurane (Forene $^{\circledR}$, Abbott Laboratories, Ottignies, Belgium), an intranasal instillation $(40 \mu \mathrm{l})$ of $1 \%$ AP (challenge) or vehicle (saline). Experimental groups are DMSO/SAL, DMSO/AP and AP/AP. The first abbreviation identifies the agent used for the dermal application on days 1 and 8 (sensitisation) and the second abbreviation identifies the agents administered via intranasal instillation on day 15 (challenge).

Each group consisted of 10 animals, five of which underwent a methacholine provocation using whole-body plethysmography, while the other five underwent a methacholine provocation using a forced oscillation technique.

The ventilatory function of each mouse was measured in a whole body plethysmograph (EMKA Technologies, Paris, France) as described previously. ${ }^{20}$ The area under the curve (AUC) of Penh (enhanced pause) against time between 0 and 40 min was calculated for each individual mouse, and this figure was used for statistical analysis.

Approximately $22 \mathrm{~h}$ later, reactivity to methacholine was assessed. In five mice per group this was done by whole-body plethysmography as described previously. ${ }^{20}$ For each mouse, Penh was plotted against methacholine concentration (from 0 to $50 \mathrm{mg} / \mathrm{ml}$ ) and the AUC was calculated. In another five mice per group, airway reactivity was measured using a forced oscillation technique (FOT) with the Flexivent system (FlexiVent, SCIREQ, Montreal, Canada). ${ }^{22}$ As previously described, airway resistance (R) was measured using a 'snapshot' protocol. For each mouse, $\mathrm{R}$ was plotted against methacholine concentration (from 0 to $10 \mathrm{mg} / \mathrm{ml}$ ) and the AUC was calculated. ${ }^{22}$

After the methacholine tests the mice were deeply anaesthetised by an intraperitoneal injection of pentobarbital (Nembutal ${ }^{\circledR}$, Sanofi Santé Animale, CEVA, Brussels, Belgium). Blood was sampled from the retro-orbital plexus, the lungs were lavaged, in situ, three times with $0.7 \mathrm{ml}$ of sterile saline, and the recovered fluid was pooled. Cells were counted and the bronchoalveolar lavage (BAL) fluid was centrifuged ( $1000 \mathrm{~g}, 10 \mathrm{~min}$ ). The supernatant was frozen $\left(-80^{\circ} \mathrm{C}\right)$ until further analyses. For differential cell counts, $250 \mu \mathrm{l}$ of the resuspended cells
(100000 cells $/ \mathrm{ml}$ ) were spun (300 g, $6 \mathrm{~min}$ ) (Cytospin 3, Shandon, TechGen, Zellik, Belgium) onto microscope slides, airdried and stained (Diff-Quik ${ }^{\circledR}$ method, Medical Diagnostics, Düdingen, Germany). For each sample, 200 cells were counted for the number of macrophages, eosinophils, neutrophils and lymphocytes.

Retroauricular, superficial cervical and mediastinal lymph nodes were obtained from the same mice. The lymph nodes from 2-3 mice were pooled and kept on ice in RPMI-1640. Cell suspensions were obtained in the same way as for the LPT. Five hundred thousand cells were stained with anti-CD3 ${ }^{+}$(allophycocyanin (APC)), anti-CD4 ${ }^{+}$(APC-Cy7), anti-CD8 ${ }^{+}$(peridinin chlorophyll protein (PerCP)-Cy5.5) and anti CD25 ${ }^{+}$(phycoerythrin (PE)), or received a single staining with anti-CD19 ${ }^{+}(\mathrm{PE})$ labelled antibodies, according to standard procedures, and with control samples being labelled with isotype-matched control antibodies. Flow cytometry (FacsArray, BD Biosciences, Erembodegem, Belgium) was performed using at least $10^{5}$ cells.

Lymphocytes were also seeded into 48-well culture plates at a density of $10^{6}$ cells $/ \mathrm{ml}$ and incubated in complete RPMI-1640 medium for $42 \mathrm{~h}$ with or without $2.5 \mu \mathrm{g} / \mathrm{ml}$ of concanavalin A (ConA) (Sigma-Aldrich, Bornem, Belgium). Cells were then centrifuged $\left(1000 \mathrm{~g}, 10 \mathrm{~min}, 4^{\circ} \mathrm{C}\right)$ and supernatants were stored at $-80^{\circ} \mathrm{C}$. Concentrations of interleukin-2 (IL-2), IL-4, IL-10, IL-13 and interferon $\gamma$ (IFN $\gamma$ ) were measured in undiluted supernatant by standard ELISA techniques, according to the manufacturer's instructions (Biosource, Nivelles, Belgium). Lower detection limits were 1.5, 1.3, 1, 0.8 and $1 \mathrm{pg} / \mathrm{ml}$ for IL-2, IL-4, IL-10, IL-13 and IFN $\gamma$, respectively.

The OptEIA Mouse IgE set from Pharmingen (BD Biosciences) was used to measure total serum IgE (diluted 1/70). Measurements were performed according to the manufacturer's instructions.

\section{Data analysis}

All data were normally distributed as assessed by the D'Agostino and Pearson omnibus normality test. All data are presented as mean \pm SD and were analysed using one-way analysis of variance (ANOVA) followed by a Dunnett posthoc test (Graphpad Prism 4.01, Graphpad Software Inc, San Diego, USA). A level of $\mathrm{p}<0.05$ (two tailed) was considered significant.

\section{RESULTS}

Figure 1 shows the cpm in the LPT when 100000 lymphocytes from the auricular lymph nodes obtained from naive, vehicletreated or AP-sensitised ( $1 \%$ or $5 \%$ ) mice were cultured for $18 \mathrm{~h}$ in the presence of $\left.{ }^{3} \mathrm{H}\right] \mathrm{TdR}$ and various concentrations of AP.

There were no significant changes in cpm counts when auricular lymphocytes from naïve or DMSO-treated mice were incubated with AP (figure 1A,B), compared with control exposure $(0 \% \mathrm{AP})$. In contrast, the lymphocytes of mice treated with $1 \%$ or $5 \%$ AP exhibited significant two- to threefold increases in cpm count upon incubation with $0.0001 \%$ and $0.001 \%$ AP, compared with the control (figure $1 \mathrm{C}, \mathrm{D})$. No proliferation was found with the highest concentration of AP (0.01\%).

In the in vivo asthma model an early ventilatory response immediately after intranasal instillation was found in AP-sensitised and challenged mice: Penh (expressed as AUC) of the completely AP-treated mice $(\mathrm{AP} / \mathrm{AP}=71 \pm 56, \mathrm{p}<0.001)$ was statistically higher than the Penh of the two control groups (DMSO/AP $=17 \pm 5$ and $\mathrm{DMSO} / \mathrm{SAL}=16 \pm 4$ ).

Methacholine airway hyper-responsiveness (AHR) was measured $22 \mathrm{~h}$ after the intranasal instillation (figure 2). AHR was determined using the whole-body plethysmograph (Penh, 
Figure 1 Lymphocyte proliferation test (LPT) on auricular lymphocytes. A lymphocyte proliferation test was performed on the auricular lymph nodes (ALNs) of naïve mice $(A)$, vehicle (dimethylsulfoxide (DMSO))-treated mice (B), 1\% ammonium persulfate (AP)-treated mice (C) and 5\% APtreated mice (D). The ALNs were cultured for $18 \mathrm{~h}$ in the presence of $\left[{ }^{3} \mathrm{H}\right]$ $\mathrm{TdR}$ and various concentrations of AP. Means $\pm S D$ are depicted; the experiment was performed in five replicates. ${ }^{*} p<0.05,{ }^{* *} p<0.01$ compared with the $0 \% \mathrm{AP}$ control group.
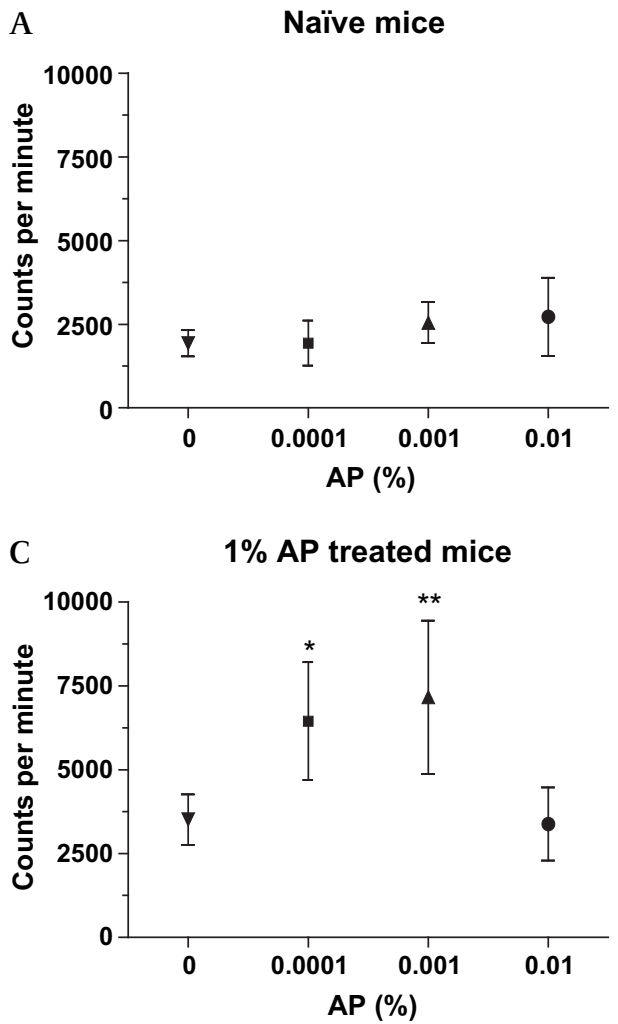

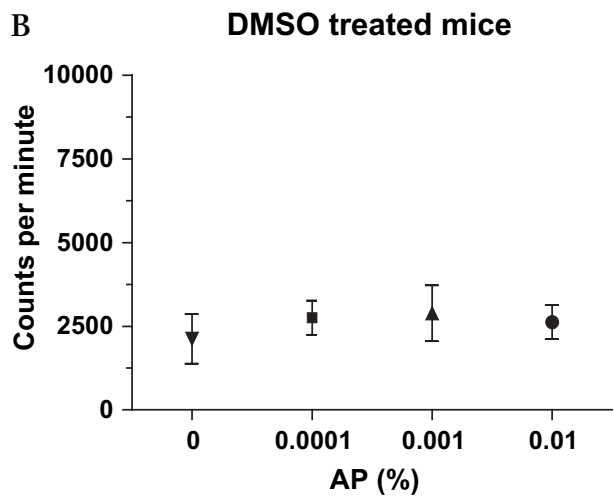

D

$5 \%$ AP treated mice

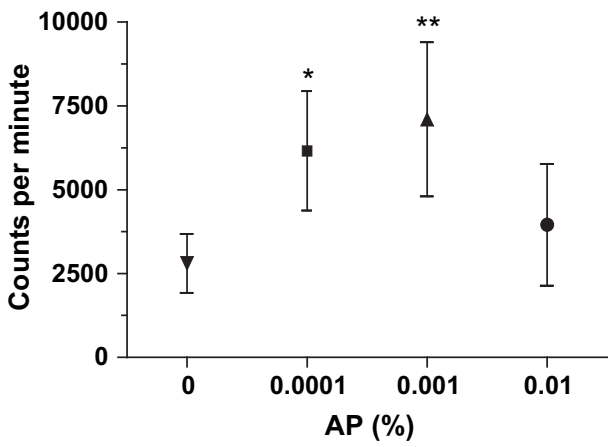

figure $2 \mathrm{~A}, \mathrm{~B})$ for half of the mice per group, and using FOT ( $\mathrm{R}$, figure $2 C, D)$ for the other half. Figure 2 shows that the AP/AP mice had a significantly increased bronchial reactivity to methacholine, compared with the control groups, using both techniques (figure $2 \mathrm{~A}, \mathrm{C}$ ). The AUC of both Penh and R (figure 2C,D) of $\mathrm{AP} / \mathrm{AP}$ mice was significantly increased compared with both control groups (DMSO/AP and DMSO/SAL).

Figure 3 shows the total and differential BAL cell count. The total number of BAL neutrophils was significantly increased in completely AP-treated (AP/AP) mice, compared with the DMSO/ AP and DMSO/SAL groups. Neither eosinophils nor lymphocytes were found in BAL.

Figure 4 shows the total numbers of $\mathrm{CD}^{+}$(T lymphocytes), $\mathrm{CD}^{+} \mathrm{CD}^{+}$(T helper (Th) lymphocytes), $\mathrm{CD}^{+} \mathrm{CD}^{+} \mathrm{CD} 25^{+}$ (activated-regulatory $\mathrm{Th}$ lymphocytes), $\mathrm{CD}^{+} \mathrm{CD}^{+}$(cytotoxic $\mathrm{T}$ (Tc) lymphocytes) and $\mathrm{CD}^{+}{ }^{+}$(B lymphocytes) cells in auricular, cervical and mediastinal lymph nodes. In both the auricular and cervical lymph nodes of completely AP-treated mice
Figure 2 Airway hyper-reactivity (AHR) to methacholine. AHR expressed as Penh (enhanced pause) was measured $22 \mathrm{~h}$ after intranasal challenge by whole-body plethysmography $(A, B)$ and $A H R$ expressed as resistance $(R)$ was measured $22 \mathrm{~h}$ after intranasal challenge by the forced oscillation technique (C, D). Left panels: mean values of Penh $\pm S D(A)$ or $R \pm S D(C)$ with increasing concentrations of methacholine. Right panels: individual values of the area under the curve (AUC) of Penh (B) or $\mathrm{R}$ (D). Experimental groups are DMSO/SAL, DMSO/AP and AP/AP. The first abbreviation identifies the agent used for dermal application (days 1 and 8) and the second identifies the agent administered intranasally (day 15). A and C: means $\pm S D, B$ and $D$ : individual values and group mean. $\mathrm{n}=4-5$ mice per group. ${ }^{*} \mathrm{p}<0.05$, ${ }^{* *} \mathrm{p}<0.01,{ }^{* * *} \mathrm{p}<0.001$ compared with DMSO/SAL and ${ }^{++} p<0.01$ compared with the DMSO/AP control group. AP, ammonium persulfate; DMSO, dimethylsulfoxide; SAL, saline.
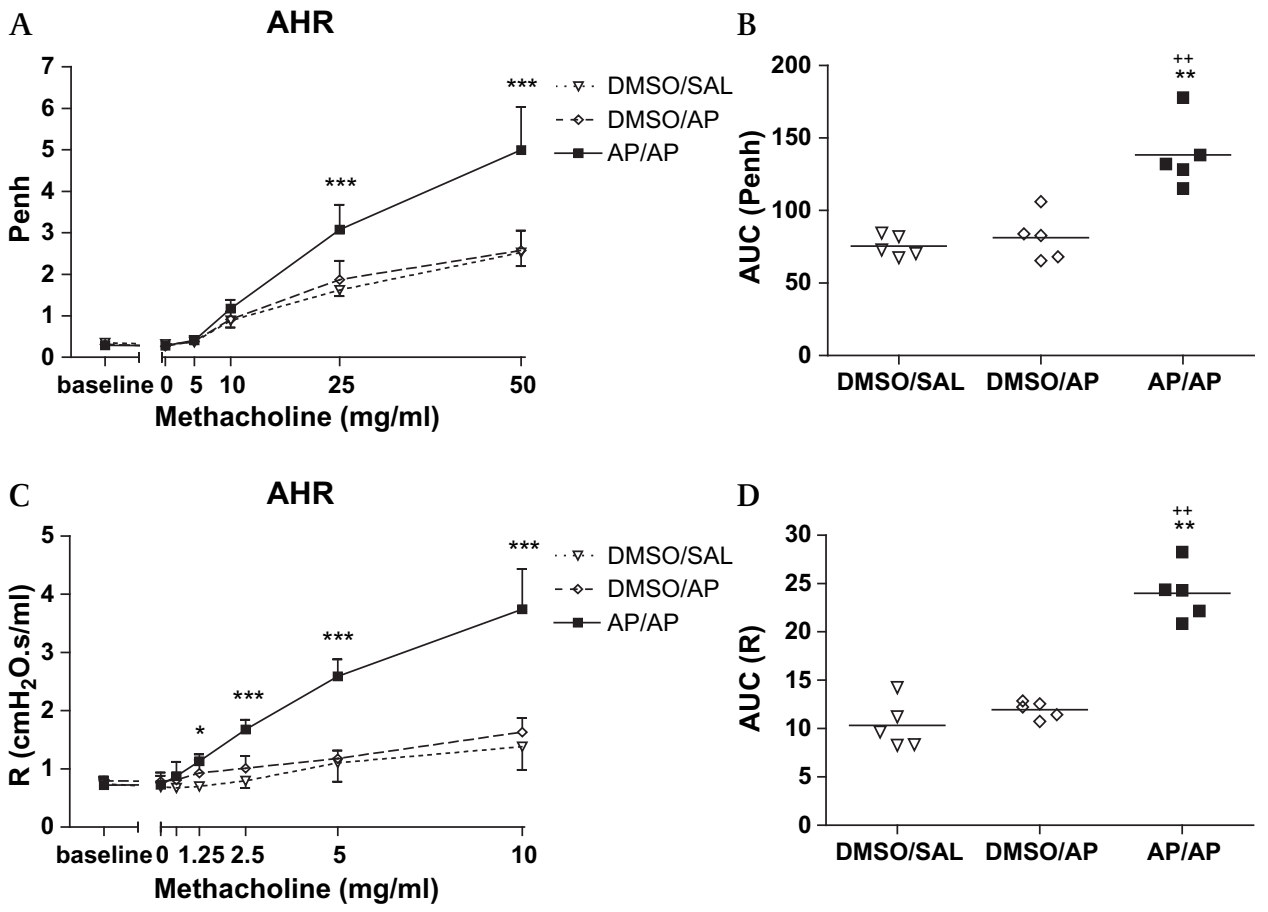


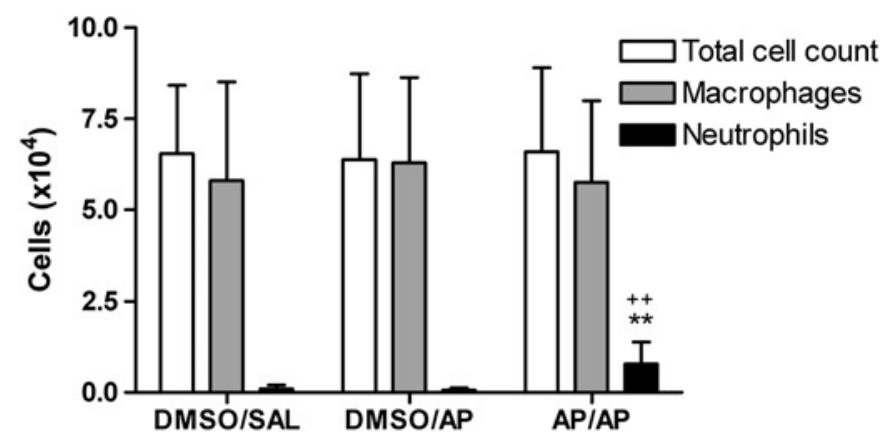

Figure 3 Total and differential bronchoalveolar lavage (BAL) cell count. Cells were obtained by BAL of the whole lung $24 \mathrm{~h}$ after intranasal challenge. BAL total cell count and differentiation between macrophages and neutrophils are presented. Experimental groups are as in figure 2. Bars are mean \pm SD. $\mathrm{n}=9-10$ mice per group. ${ }^{* *} \mathrm{p}<0.01$ compared with the DMSO/SAL group and ${ }^{++} p<0.01$ compared with DMSO/AP. AP, ammonium persulfate; DMSO, dimethylsulfoxide; $S A L$, saline.

a significant increase was found in both $\mathrm{T}$ and $\mathrm{B}$ lymphocytes (figure $4 \mathrm{~B}, \mathrm{C}$ ), compared with the control groups. The increase in $T$ lymphocytes was a result of a significant increase in all three subpopulations measured (Th, $\mathrm{T}$ regulatory (Treg) and $\mathrm{Tc}$ lymphocytes). Mediastinal lymph nodes did not show any difference between the three treatment groups, but the numbers were low (figure 4D).

Table 1 shows the concentration of several cytokines measured in the supernatant of auricular, cervical and mediastinal lymphocytes that were cultured for $42 \mathrm{~h}$ with ConA. Significantly lower IL-2 concentrations and higher IL-4 concentrations were measured in auricular as well as cervical lymphocytes of the $\mathrm{AP} / \mathrm{AP}$ group, compared with both control groups (DMSO/AP and DMSO/SAL). A higher amount of IL-10 and IL-13 was found only in auricular lymphocytes of AP/AP mice compared with the DMSO/SAL group.

Figure 5 shows that total serum IgE was increased (3.5- and 2fold) in the completely AP-treated mice (AP/AP) compared with DMSO/SAL and DMSO/AP mice.

\section{DISCUSSION}

Although occupational asthma caused by persulfate salts is relatively frequent in hairdressers, little or no experimental work has been done to understand sensitisation and the mechanisms of this form of chemical-induced asthma. Here, we have demonstrated that lymphocytes obtained from the draining lymph nodes of dermally AP-sensitised mice can be stimulated to
Figure 4 Lymphocyte subpopulations in auricular, cervical and mediastinal lymph nodes. The lymph nodes were collected $24 \mathrm{~h}$ after the intranasal challenge and 2-3 mice were pooled. Five hundred thousand auricular lymphocytes (A, B), cervical lymphocytes (C) and mediastinal lymphocytes (D) were stained with anti$\mathrm{CD}^{+}$(T lymphocytes), anti-CD3 ${ }^{+} \mathrm{CD}^{+}$ (T helper (Th) lymphocytes), anti$\mathrm{CD}^{+}{ }^{\mathrm{CD}} 4^{+} \mathrm{CD} 25^{+}$

(activated-regulatory Th lymphocytes) and anti-CD ${ }^{+} \mathrm{CDB}^{+}$(cytotoxic T (Tc) lymphocytes) or were stained with a single anti-CD19 ${ }^{+}$(B lymphocytes). Experimental groups are as in figure 2. $\mathrm{n}=3-4$ experiments per group. Bars show mean $\pm S D$. ${ }^{*} p<0.05,{ }^{* *} p<0.01$ compared with the DMSO/SAL control group and ${ }^{+} p<0.05,{ }^{++} p<0.01$ compared with the DMSO/AP group. $\mathrm{AP}$, ammonium persulfate; DMSO, dimethylsulfoxide; $\mathrm{SAL}$, saline.
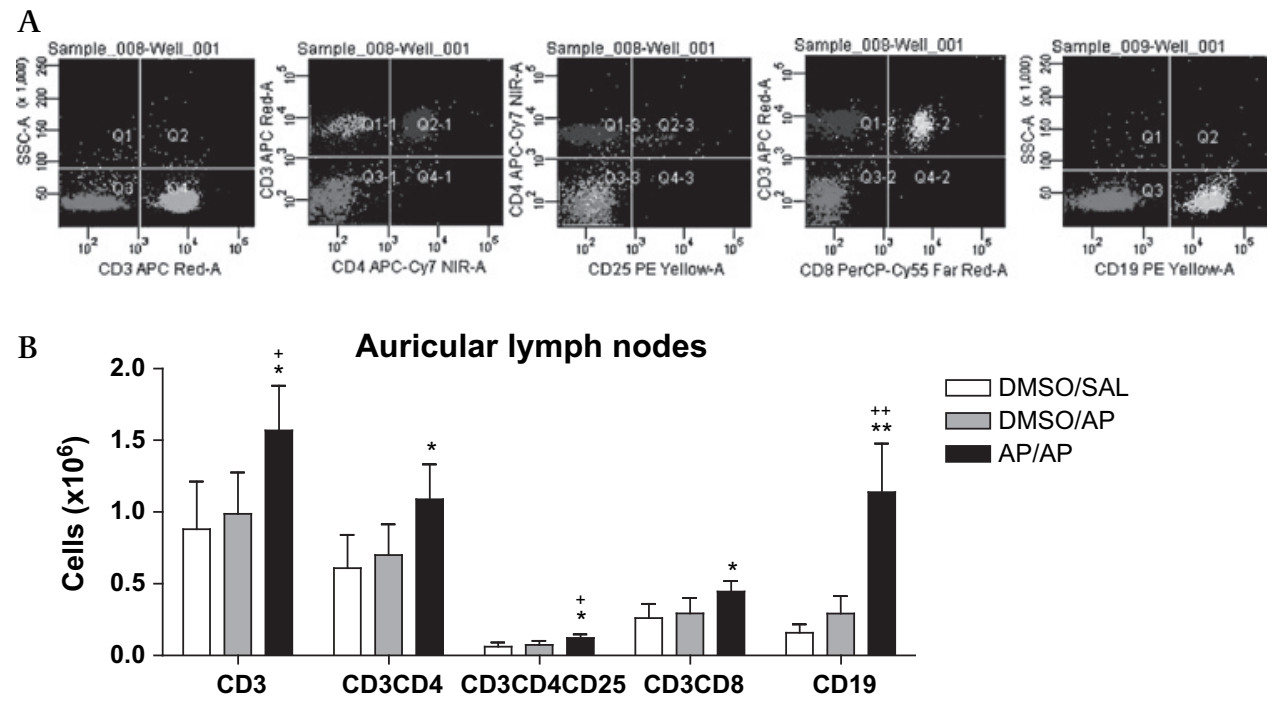

C

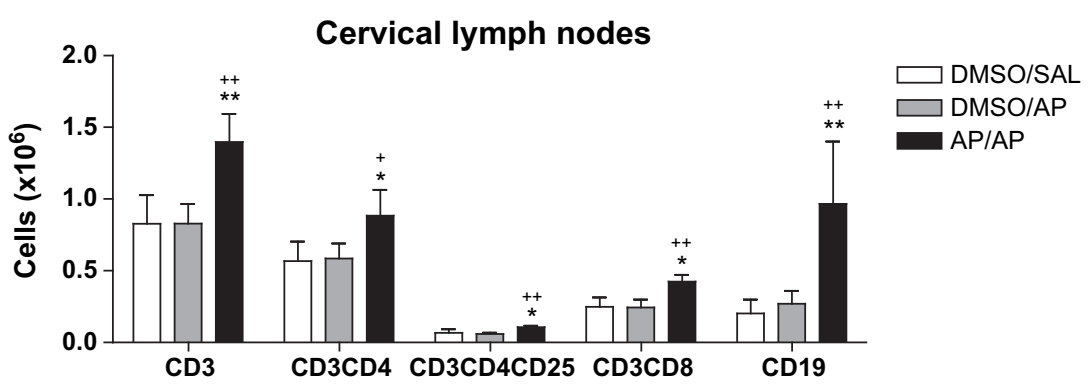

D

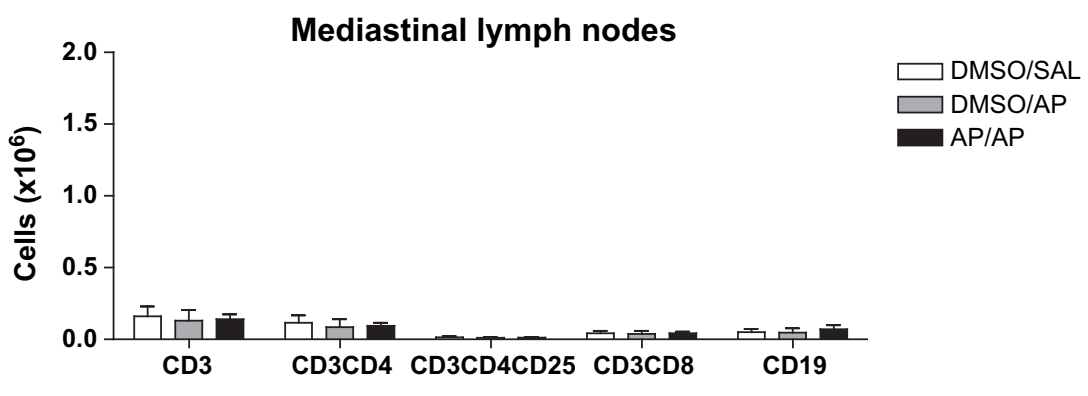


Table 1 Cytokine levels in supernatants of auricular, cervical and mediastinal lymphocytes

\begin{tabular}{lccc}
\hline & DMSO/SAL & DMSO/AP & AP/AP \\
\hline Auricular LNCs & & & \\
IL-2 (pg/ml) & $645.9 \pm 164.6$ & $587.6 \pm 113.3$ & $168.5 \pm 118.0^{* *} \dagger+$ \\
IL-4 (pg/ml) & $24.6 \pm 3.5$ & $23.8 \pm 8.4$ & $44.1 \pm 11.6^{*} \dagger$ \\
IL-10 (pg/ml) & $26.8 \pm 14.7$ & $37.2 \pm 23.1$ & $82.1 \pm 35.2^{*} \dagger$ \\
IL-13 (pg/ml) & $28.8 \pm 11.0$ & $42.6 \pm 13.7$ & $75.7 \pm 40.8^{*}$ \\
IFN $\gamma(\mathrm{pg} / \mathrm{ml})$ & $817.6 \pm 14.0$ & $1202 \pm 751.3$ & $1523 \pm 1560$ \\
Cervical LNCs & & & \\
IL-2 (pg/ml) & $538.4 \pm 83.6$ & $572.9 \pm 189.4$ & $214.7 \pm 172.2^{*} \dagger \dagger$ \\
IL-4 (pg/ml) & $20.5 \pm 5.7$ & $28.9 \pm 6.2$ & $44.6 \pm 20.0^{*}$ \\
IL-10 (pg/ml) & $48.9 \pm 48.7$ & $107.3 \pm 52.2$ & $98.9 \pm 91.5$ \\
IL-13 (pg/ml) & $36.4 \pm 3.4$ & $74.5 \pm 45.3$ & $75.8 \pm 36.2$ \\
IFN $\gamma(\mathrm{pg} / \mathrm{ml})$ & $978.4 \pm 522$ & $1650.0 \pm 944.8$ & $1202.0 \pm 988.7$ \\
Mediastinal LNCs & & & \\
IL-2 (pg/ml) & $456.3 \pm 30.4$ & $293.1 \pm 57.2$ & $307.8 \pm 195.4$ \\
IL-4 (pg/ml) & $24.7 \pm 7.5$ & $43.0 \pm 23.6$ & $37.5 \pm 18.6$ \\
IL-10 (pg/ml) & ND & ND & ND \\
IL-13 (pg/ml) & $54.4 \pm 7.7$ & $53.5 \pm 6.7$ & $44.9 \pm 13.0$ \\
IFN $\gamma(\mathrm{pg} / \mathrm{ml})$ & $324.4 \pm 133.4$ & $245.6 \pm 200.0$ & $258.5 \pm 241.6$ \\
\hline
\end{tabular}

The lymph nodes of $2-3$ mice were pooled and the obtained LNCs were cultured $(42 \mathrm{~h})$ with concanavalin $\mathrm{A}(2.5 \mu \mathrm{g} / \mathrm{ml})$.

IL-2, IL-4, IL-10, IL-13 and IFN $\gamma$ were measured in LNC supernatant by ELISA. Experimental groups are as in figure 2. Data are presented as mean $\pm S D$. $n=3-5$ values per group.

${ }^{*} \mathrm{p}<0.05,{ }^{* *} \mathrm{p}<0.01$ compared with the DMSO/SAL group and

$+p<0.05,+\dagger p<0.01$ compared with the DMSO/AP group.

AP, ammonium persulfate; DMSO, dimethylsulfoxide; IL, interleukin; IFN interferon; LNCs. lymph node cells; ND, not detectable; SAL, saline.

proliferate when challenged in vitro with the sensitising agent (AP). Furthermore, we have shown that in vivo intranasal challenge in such dermally sensitised mice leads to an immediate early ventilatory response, followed by increased reactivity to methacholine $22 \mathrm{~h}$ later, which is accompanied by an increase in the number of neutrophils, increased numbers of $T$ and $B$ lymphocytes in auricular and cervical draining lymph nodes and an increase in total serum IgE.

Persulfates are low molecular weight strong oxidising agents that are used by chemical workers and hairdressers mainly for bleaching processes. ${ }^{23}$ Not only skin diseases such as contact dermatitis, but also respiratory disorders have been reported after exposure to persulfates. ${ }^{10-16}$ Workers who are exposed to persulfate salts are at high risk of developing $\mathrm{OA}$, although the mechanism of the induction of asthma is not well understood. ${ }^{14}$ The latency period between the onset of exposure and onset of symptoms, and the type of response observed in challenge tests suggest that persulfate-induced $\mathrm{OA}$ is mediated by an immunological mechanism. ${ }^{13} 1424$ It is possible that in some patients the mechanism is IgE mediated, since positive skin prick tests to persulfates have been obtained in some studies. ${ }^{12} \quad \begin{array}{llll}13 & 15 & 16\end{array}$ Wrbitzky et al found, in a study of employees of a persulfate manufacturing plant, that $15 \%$ of workers developed a positive skin prick test reaction and these subjects also had a lower lung function. ${ }^{25}$ Furthermore, elevated total serum IgE levels and anaphylactic reactions upon exposure to persulfates have also been described. ${ }^{8}{ }^{15}$ However, non-IgE-mediated mechanisms may also be involved because clinically positive patients do not always have positive skin prick tests. Moreover, Yawalkar et al suggested that $\mathrm{T}$ lymphocytes may be directly involved in mediating inflammatory processes in the airways based on the results of lymphocyte proliferation analyses. ${ }^{8}$

Classically, adverse effects of inhaled chemicals on the respiratory system have been assumed to be induced by inhalation exposure. However, more recent data support the potential for dermal exposure to lead to respiratory tract sensitisation. ${ }^{26} 27$

\section{Total serum IgE}

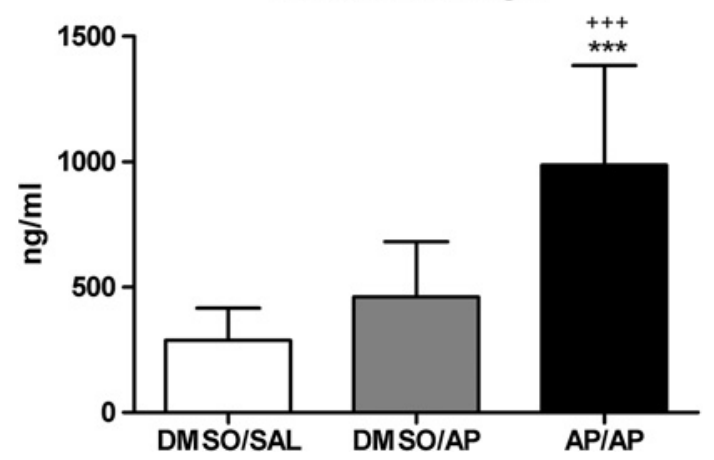

Figure 5 Total serum immunoglobulin E ( $\lg E)$ levels. Blood was collected $24 \mathrm{~h}$ after the intranasal challenge. Total serum IgE was measured using a standard ELISA. Experimental groups are as in figure 2. Bars show mean \pm SD. $n=9-10$ mice per group. ${ }^{* *} \mathrm{p}<0.001$ compared with the DMSO/SAL group and ${ }^{+++} p<0.001$ compared with the DMSO/ AP control group. AP, ammonium persulfate; DMSO, dimethylsulfoxide; SAL, saline.

Experimental support for such a mechanism has been provided by several research groups, who demonstrated in mice that respiratory responses to inhaled isocyanates depend on prior frequency and concentration of dermal sensitisation. ${ }^{19-21} 28-30$ In hairdressers, occupational skin diseases such as dermatitis have been described in those with OA cause by persulfate salts. $^{9-11}$ In most of these cases, dermal sensitisation occurred prior to the development of asthma. Previously, we showed that ammonium persulfate is a moderate dermal sensitiser, according to the local lymph node assay (LLNA). ${ }^{18}$

Vanoirbeek et al developed a mouse model of chemical-induced asthma in which dermal sensitisation is followed by a single challenge. The model reproduces several of the main characteristics of human occupational asthma, namely the occurrence of an early ventilatory response, non-specific AHR and airway inflammation. ${ }^{19-21}$ The fact that AP responded positively in this model is a further validation of this model of chemical-induced asthma. In addition, we showed that lymphocytes responded directly on in vitro AP stimulation in an LPT. In our previous experiments we were not able to verify sensitisation in vitro because toluene diisocyanate (TDI) is not stable in an aqueous milieu. Combining the LPT and mouse model results, we can presume that the responses in the latter depend on AP-specific lymphocyte activation. Furthermore, we previously described the importance of lymphocytes in this mouse model, since severe combined immune deficiency (SCID) mice did not show airway or inflammatory responses. ${ }^{20}$ After AP sensitisation and challenge the mice showed an increase in total serum IgE, as well as an increase in the total amount of B and T lymphocytes, and IL-4, IL-10 and IL-13 levels. Increased IL-10 also suggests the development of inducible Treg lymphocytes, which probably reflects the increase in $\mathrm{CD} 4{ }^{+} \mathrm{CD} 25^{+}$lymphocytes in the auricular lymph nodes. AP-sensitised and challenged mice showed a clear AHR and an increase in IL-13 concentration, which are linked to each other. ${ }^{31}$ Decreasing levels of IL-2 suggest an inhibition of the Th1 pathway but this was not confirmed by the IFN $\gamma$ concentrations, which were slightly increased although not significantly, due to variability between mice in the same group. Previously, we described that TDI and trimellitic anhydride (TMA), both known strong dermal and respiratory sensitisers, caused an increase in both IL-4 and IFN $\gamma$, suggesting a mixed Th1-Th2 stimulation. ${ }^{19}$ This is not the case for AP. Nevertheless, we do confirm the outcome of human studies on AP, in which both 
total serum IgE and T lymphocytes were shown to be involved in AP-induced OA. ${ }^{8}$

The cellular composition of the BAL after AP sensitisation and challenge in our model is not entirely typical for an immunologically mediated asthmatic response, since there was mainly an increase in neutrophils but no increase in eosinophils or lymphocytes. Several research groups, including ourselves, already observed this type of neutrophilic inflammation in murine models of chemical-induced asthma. ${ }^{202232-34}$ Moreover, it has been established that, in humans, eosinophils are not always increased and that neutrophilia is also an important feature of OA. ${ }^{145}$ Thus, asthma caused by low molecular weight chemicals can be separated into eosinophilic and non-eosophilic variants, with the latter predominating. ${ }^{36}$ In a population of hairdressers, Moscato et al showed that persulfate salts used in hair bleaching products are important agents involved in the development of $\mathrm{OA}$ and rhinitis. Sputum eosinophilia was associated with more severe disease and greater bronchodilator reversibility. In $\mathrm{OA}$ in hairdressers the severity of the disease is not so high and these data could be related to the fact that persulfate salts produce a neutrophilic inflammation in lungs and probably a less severe disease. ${ }^{146}$ We think that the nature of the pulmonary inflammation in asthma is presumably heavily dependent on the time course of the disease, the pattern of the exposure and individual susceptibility factors.

In conclusion, we have shown that ammonium persulfate, after two dermal applications and only a single airway challenge, can induce features of human occupational asthma in a mouse model. These features include AHR, neutrophilic inflammation, increased levels of total serum IgE, and $\mathrm{T}$ and $\mathrm{B}$ cell-specific responses. The complete mechanisms of these reactions remain to be elucidated. The consequences of exposure to persulfates are not to be underestimated, for example contact dermatitis and $\mathrm{OA}$, and proper protection-also of the skin - must be considered.

Funding The project was supported by a grant from the Interuniversity Attraction Pole Program, Belgian State, Belgian Science Policy P6/35, from the 'Fonds voor Wetenschappelijk Onderzoek Vlaanderen' (FWO), FWO G.0547.08, from the Fundació Catalana de Pneumologia (FUCAP), from the Societat Catalana de Pneumología (SOCAP) and from FIS PI080730. JV is a postdoctoral fellow of the FWO.

Competing interests None.

Provenance and peer review Not commissioned; externally peer reviewed.

\section{REFERENCES}

1. Mapp CE, Boschetto P, Maestrelli P, et al. Occupational asthma. Am J Respir Crit Care Med 2005;172:280-305.

2. Bardana EJ Jr. Occupational asthma and allergies. J Allergy Clin Immunol 2003;111 (2 Suppl):S530-9.

3. Chan-Yeung M, Malo JL, Tarlo SM, et al. Proceedings of the first Jack Pepys Occupational Asthma Symposium. Am J Respir Crit Care Med 2003;167:450-71.

4. Lombardo LJ, Balmes JR. Occupational asthma: a review. Environ Health Perspect 2000:108(Suppl 4):697-704.

5. McDonald JC, Chen $Y$, Zekveld $C$, et al. Incidence by occupation and industry of acute work related respiratory diseases in the UK, 1992-2001. Occup Environ Med 2005;62:836-42.

6. Ameille J, Pauli G, Calastreng-Crinquand A, et al. Reported incidence of occupational asthma in France, 1996-99: the ONAP programme. Occup Environ Med 2003;60:136-41.

7. Orriols R, Costa R, Albanell $\mathrm{M}$, et al. Reported occupational respiratory diseases in Catalonia. Occup Environ Med 2006;63:255-60.
8. Yawalkar N, Helbling A, Pichler CE, et al. T cell involvement in persulfate triggered occupational contact dermatitis and asthma. Ann Allergy Asthma Immunol 1999:82:401-4.

9. Aalto-Korte K, Makinen-Kiljunen S. Specific immunoglobulin E in patients with immediate persulfate hypersensitivity. Contact Dermatitis 2003;49:22-5.

10. Uter W, Lessmann $\mathrm{H}$, Geier J, et al. Contact allergy to ingredients of hair cosmetics in female hairdressers and clients-an 8-year analysis of IVDK data. Contact Dermatitis 2003; 49:236-40

11. Valks R, Conde-Salazar L, Malfeito J, et al. Contact dermatitis in hairdressers, 10 years later: patch-test results in 300 hairdressers (1994 to 2003) and comparison with previous study. Dermatitis 2005;16:28-31.

12. Munoz X, Cruz MJ, Orriols $\mathrm{R}$, et al. Occupational asthma due to persulfate salts: diagnosis and follow-up. Chest 2003;123:2124-9.

13. Blainey AD, Ollier $\mathrm{S}$, Cundell $\mathrm{D}$, et al. Occupational asthma in a hairdressing salon Thorax 1986:41:42-50.

14. Moscato G, Pignatti $P$, Yacoub MR, et al. Occupational asthma and occupational rhinitis in hairdressers. Chest 2005;128:3590-8.

15. Fisher AA, Dooms-Goossens A. Persulfate hair bleach reactions. Cutaneous and respiratory manifestations. Arch Dermatol 1976;112:1407-9

16. Pepys J, Hutchcroft BJ, Breslin AB. Asthma due to inhaled chemica agents - persulphate salts and henna in hairdressers. Clin Allergy 1976;6:399-404.

17. Parra FM, Igea JM, Quirce $S$, et al. Occupational asthma in a hairdresser caused by persulphate salts. Allergy 1992;47:656-60.

18. Cruz MJ, De Vooght V, Munoz X, et al. Assessment of the sensitization potential of persulfate salts used for bleaching hair. Contact Dermatitis 2009;60:85-90.

19. Vanoirbeek JA, Tarkowski M, Vanhooren HM, et al. Validation of a mouse model of chemical-induced asthma using trimellitic anhydride, a respiratory sensitizer, and dinitrochlorobenzene, a dermal sensitizer. J Allergy Clin Immunol 2006:117:1090-7.

20. Tarkowski M, Vanoirbeek JAJ, Vanhooren HM, et al. Immunological determinants of ventilatory changes induced in mice by dermal sensitization and respiratory challenge with toluene diisocyanate. Am J Physiol Lung Cell Mol Physiol 2007:292:L207-14.

21. Vanoirbeek JA, De Vooght V, Vanhooren HM, et al. How long do the systemic and ventilatory responses to toluene diisocyanate persist in dermally sensitized mice? J Allergy Clin Immunol 2008;121:456-63.

22. Vanoirbeek JA, Rinaldi M, De Vooght V, et al. Noninvasive and invasive pulmonary function in mouse models of obstructive and restrictive respiratory diseases. Am J Respir Cell Mol Biol 2010;42:94-104

23. Mensing $\mathbf{T}$, Marek W, Baur $X$. The influence of ammonium persulfate on guinea pig tracheal muscle tone: release of nitric oxide. Pharmacol Toxicol 1996: 78:336-40.

24. Leino T, Tammilehto $\mathrm{L}$, Hytonen $\mathrm{M}$, et al. Occupational skin and respiratory diseases among hairdressers. Scand J Work Environ Health 1998;24:398-406.

25. Wrbitzky R, Drexler $\mathrm{H}$, Letzel $\mathrm{S}$. Early reaction type allergies and diseases of the respiratory passages in employees from persulphate production. Int Arch Occup Environ Health 1995;67:413-17.

26. Redlich CA, Herrick CA. Lung/skin connections in occupational lung disease. Curr Opin Allergy Clin Immunol 2008;8:115-19

27. Bello D, Herrick CA, Smith TJ, et al. Skin exposure to isocyanates: reasons for concern. Environ Health Perspect 2007;115:328-35.

28. Pauluhn J. Brown Norway rat asthma model of diphenylmethane-4,4'-diisocyanate (MDI): impact of vehicle for topical induction. Regul Toxicol Pharmacol 2008; 50:144-54

29. Pauluhn J. Brown Norway rat asthma model of diphenylmethane-4,4'-diisocyanate (MDI): analysis of the elicitation dose-response relationship. Toxicol Sci 2008;104:320-31.

30. Ban M, Morel G, Langonne I, et al. TDI can induce respiratory allergy with Th2-dominated response in mice. Toxicology 2006;218:39-47.

31. Akbari 0, Stock P, Meyer E, et al. Essential role of NKT cells producing IL-4 and IL-13 in the development of allergen-induced airway hyperreactivity. Nat Med 2003;9:582-8.

32. Vanoirbeek JA, De Vooght V, Nemery B, et al. Multiple challenges in a mouse mode of chemical-induced asthma lead to tolerance: ventilatory and inflammatory responses are blunted, immunologic humoral responses are not. Toxicology 2009;257:144-52

33. Matheson JM, Johnson VJ, Vallyathan V, et al. Exposure and immunological determinants in a murine model for toluene diisocyanate (TDI) asthma. Toxicol Sci 2005;84:88-98.

34. Ban M, Hettich D. Effect of Th2 cytokine antagonist treatments on chemical-induced allergic response in mice. J Appl Toxicol 2005:25:239-47.

35. Park H, Jung K, Kim H, et al. Neutrophil activation following TDI bronchial challenges to the airway secretion from subjects with TDI-induced asthma. Clin Exp Allergy 1999;29:1395-401.

36. Anees W, Huggins V, Pavord ID, et al. Occupational asthma due to low molecular weight agents: eosinophilic and non-eosinophilic variants. Thorax 2002:57:231-6. 